\title{
The Use of Google Docs In The Context Of COVID 19 Pandemic For The Assessment of Prolonged Fatigue After Infection: A Survey Study
}

\author{
${ }^{1}$ Shaimaa Abdalaleem Abdelgeleel, ${ }^{1}$ Dalia N. Eldin, ${ }^{2}$ Heba Abubakr M. Salama \\ ${ }^{1}$ Department of Biostatistics and Epidemiology, National Cancer Institute, Cairo University. \\ ${ }^{2}$ Medical-Surgical Nursing, Faculty of Nursing, Mansoura University, Egypt.
}

Submission Date: 04-03-2021 Revision Date: 02-05-2021 Acceptance Date: 03-05-2021

\begin{abstract}
Background: Whilst the globe is facing the second wave of COVID-19 and fears of a potential third wave, patients who were previously infected and recovered from the infection were inadvertently overlooked. Fatigue is one of the most common recognized complaints associated with Coronavirus infection and it has lasted for a variable period after recovery. Objective: To assess the frequency of fatigue post-COVID-19 and whether the period after full recovery and the duration of symptoms affects the severity of fatigue. Method: The current study is a cross-sectional survey. Google form was constructed to build online questionnaires. It included sociodemographic data and the 10 questions of the Fatigue Assessment Scale. Participants were also asked about the duration of symptoms and recovery time. Results: The study enrolled 215 participants. The mean age of the participants was $38.4 \pm 12.6$ years, 150 females (69.8\%) and 65 males $(30.2 \%)$. The most presenting symptom was bony ache $(74.0 \%)$. The mean fatigue score was 36.0 and ranged from (12-50). There was no significant association between sociodemographic data items and the fatigue assessment scale. A statistically significant negative association was found between the time after COVID-19 recovery and the Fatigue Assessment Scale. However, there was a statistically significant positive correlation between the duration of symptoms and the Fatigue Assessment Scale. Conclusion: Post-COVID-19 fatigue has been common after recovery from the novel coronavirus infection. The sociodemographic variables did not affect the fatigue score. Prolonged fatigue was associated with a longer duration of symptoms; however, it decreases over time after recovery.
\end{abstract}

Keywords: Coronavirus, fatigue, time after recovery.

Corresponding Author: Shaimaa Abdalaleem Abdelgeleel Email: bossykhaled1@hotmail.com

\section{Introduction}

Pneumonia caused by severe acute respiratory syndrome Coronavirus-2 (SARS-CoV-2), the causative virus of Coronavirus disease 2019 (COVID-19) was newly diagnosed at the beginning of 2019 and was characterized by acute and widespread respiratory syndrome. ${ }^{1}$ By the end of May 2020, more than 5.5 million confirmed cases of COVID-19 and more than 353,000 deaths worldwide had been recorded. According to the average number of cases in August 2020, Egypt is one of the top 40 countries in the world. ${ }^{2}$ The main manifestations of Coronavirus are dry cough, fever, fatigue, or bony ache and shortness of breath, or difficulty breathing. ${ }^{3,4}$ Fatigue is recognized as one of the most common complaints of patients infected with SARS-CoV-2. Fatigue is a subjective and relatively nonspecific disabling symptom, characterized by an alleviated capacity for work and reduced efficiency of accomplishment, and is usually accompanied by a feeling of weariness and tiredness. Disabling fatigue can have a significant impact on patient's everyday activities, as well as on his professional

$\begin{array}{llll}\text { Vol. } 40 & \text { No. } 1 & \text { January } & 2022\end{array}$


and social life, leading to lower life quality. ${ }^{5,6}$

In a report on the clinical features of the infected patients, $40.3 \%$ of them presented with fatigue. ${ }^{7,8}$ The exact mechanism of what causes post-viral fatigue remains undetermined. Many theories have been proposed in an attempt to explain the association between fatigue and viral infection. The release of chemicals and cytokines by the body's immune system as a part of the immune response to viral infection is one of the theories demonstrating the cause of fatigue and lack of energy in individuals. ${ }^{9}$ The effect of quarantine on cases of COVID-19 infection can also lead to the development of post-COVID-19 depression, prolonged fatigue, and anxiety. ${ }^{10}$

Long-term COVID or post-COVID syndrome is defined by the National Institute for Health and Care Excellence as a wide range of signs and symptoms that occur during or after an infection associated with COVID -19 and persist for more than 3 months. In addition, it may be related to residual inflammation, organ injury, non-specific effects of social isolation, hospitalization, or an influence on pre-existing health conditions. ${ }^{11,12}$

The presentation of the post-COVID-19 syndrome varies significantly from nonspecific symptoms such as bony pain, insomnia, fatigue, cough, and breathlessness, to more specific organrelated symptoms, such as orthopnea, leg swelling, and exercise intolerance due to COVID-19 induced heart failure. Also, pulmonary embolism can cause chest pain and severe breathlessness. Palpitations with mild exertion, night sweats, and poor temperature regulation were all identified as autonomic symptoms. ${ }^{13,14}$

This survey aims to assess the frequency of fatigue post-COVID-19 and whether the period after full recovery and the duration of symptoms affect fatigue severity.

\section{Method}

This cross-sectional survey assessed the frequency of fatigue post-COVID-19 and whether the period after full recovery and the duration of symptoms affect fatigue severity. The study was conducted from the $4^{\text {th }}$ of November to the $29^{\text {th }}$ of November 2020.

A convenience sample of 215 COVID-19 patients included patients of both genders, aged 16-80 years, who can read and write to complete the scales after complete recovery from COVID-19 (negative PCR). The study excluded individuals with general medical conditions such as chronic diseases that could be manifested by fatigue (renal disease, diabetes, hepatic disease, heart disease, cancer and hypothyroidism) as well as patients who did not perform PCR test after recovery. The study population was recruited from those who had recovered and discharged from the 4 isolation hospitals. A list of recovering patients was obtained from 4 hospitals. Individuals were invited to respond to the survey via emails and social media platforms such as WhatsApp. They have been informed of the content of the questionnaire and that the link will be available online during November 2020.

We used Google docs as an online survey constructing tool. The main benefits of Google docs are that it is easy to use, widely available, saves time and money, and is safe to use in the context of the COVID-19 pandemic. To our knowledge, the use of Google docs as a method for studying fatigue after recovery from a COVID-19 infection has not been reported before. In these circumstances, the primary concern is the safety of the clinical researchers and the community they interact with because a face-to-face interview is quite risky. Google docs applications are certified by the Federal Information Security Management Act (FISMA), SAS 70 Type II certification, and US/EU Safe harbor certification. ${ }^{15}$ 
Table 1: Sociodemographic data among the studied group

\begin{tabular}{|c|c|}
\hline Characteristic & $\begin{array}{c}\text { Total } \\
(n=215)\end{array}$ \\
\hline \multicolumn{2}{|l|}{ Age (years) } \\
\hline Mean \pm SD & $38.4 \pm 12.6$ \\
\hline Median (range) & $37.0(16-79)$ \\
\hline \multicolumn{2}{|l|}{ Age groups } \\
\hline$<30$ & $51(23.7 \%)$ \\
\hline $30-40$ & $98(45.6 \%)$ \\
\hline$>40$ & $66(30.7 \%)$ \\
\hline \multicolumn{2}{|l|}{ Sex } \\
\hline Female & $150(69.8 \%)$ \\
\hline Male & $65(30.2 \%)$ \\
\hline \multicolumn{2}{|l|}{ Marital status } \\
\hline Single & $48(22.3 \%)$ \\
\hline Married & $154(71.6 \%)$ \\
\hline Widow & $7(3.3 \%)$ \\
\hline Divorced & $6(2.8 \%)$ \\
\hline \multicolumn{2}{|l|}{ Occupation } \\
\hline Employed & $137(63.7 \%)$ \\
\hline Not employed & $65(30.2 \%)$ \\
\hline Students & $13(6.1 \%)$ \\
\hline \multicolumn{2}{|c|}{ Type of employment $(n=137)$} \\
\hline Doctor & $45(32.8 \%)$ \\
\hline Teacher & $22(16.1 \%)$ \\
\hline Engineer & $12(8.8 \%)$ \\
\hline Manger & $11(8.1 \%)$ \\
\hline Nurse & $6(4.4 \%)$ \\
\hline Pharmacist & $6(4.4 \%)$ \\
\hline Others* & $35(25.5 \%)$ \\
\hline
\end{tabular}

Values are presented as mean $\pm S D$, average (range), or number (\%). *Other works include: seller, Tour guide, jeweller, and Chef.

The online questionnaire included clarification of the purpose of the study, sociodemographic data, symptoms, and the ten questions of the Fatigue Assessment Scale. This scale was developed by Michielsen et al. ${ }^{16}$ Each item on the scale is answered using a fivepoint, Likert-type scale ranging from 1 ("never") to 5 ("always"). Items 4 and 10 are reverse scored. Total scores can range from 10, indicating the lowest level of fatigue, to 50, which indicates the highest. Scores between 22 and 34 indicate mild to moderate fatigue, whereas scores of 35 as a minimum indicate severe fatigue. ${ }^{17}$ Although there are several validated fatigue rating scales, a comprehensive review of 30 published scales provided by
Table 2: The severity and main presenting symptoms among the participants

\begin{tabular}{|c|c|}
\hline & $\begin{array}{c}\text { Total } \\
(n=215) \\
\end{array}$ \\
\hline \multicolumn{2}{|l|}{ Symptoms* } \\
\hline Bone ache & $159(74.0 \%)$ \\
\hline Cough & $130(60.5 \%)$ \\
\hline Fever & $121(56.3 \%)$ \\
\hline Shortness of breath & $118(54.9 \%)$ \\
\hline Headache & $94(43.7 \%)$ \\
\hline $\begin{array}{l}\text { Gastrointestinal } \\
\text { symptoms** }\end{array}$ & $123(57.2 \%)$ \\
\hline Loss of taste and smell & $80(37.2 \%)$ \\
\hline Others*** & $94(43.7 \%)$ \\
\hline Need ICU admission & $43(20.0 \%)$ \\
\hline $\begin{array}{l}\begin{array}{l}\text { Duration of } \\
\text { (days) }\end{array} \\
\text { (dymptoms }\end{array}$ & $18(7.0-40.0)$ \\
\hline $\begin{array}{l}\text { Duration after recovery } \\
\text { (days) }\end{array}$ & $40.0(15.0-180.0)$ \\
\hline Exposure to reinfection & $16.0(7.4 \%)$ \\
\hline $\begin{array}{l}\begin{array}{l}\text { Duration of reinfection } \\
\text { (months) }\end{array} \\
\end{array}$ & $4.0(3.0-6.0)$ \\
\hline
\end{tabular}

Values are presented as mean (range) or number (\%), ICU: intensive care unit. *ONE person may have more than one symptom. ${ }^{* *}$ Gastrointestinal symptoms include (vomiting, diarrhea, and abdominal pain). *** Other symptoms include rash, chest pain, numbness, and sore throat.

Dittner et al. ${ }^{18}$, the Fatigue Assessment Scale was found to be the most promising fatigue indicator with high reliability and validity, and it has been proven to be unidimensional without sex bias in both healthy control and diseased population. ${ }^{19-21}$ It is a simple self-report fatigue questionnaire, easy to complete and not time-consuming as it takes approximately two minutes to fill out. The digital version of the Fatigue Assessment Scale is available online in 20 languages, including the Arabic version.

Furthermore, participants were asked about the duration of symptoms and recovery time, negative PCR, and chronic disease. The duration of reinfection was calculated after complete recovery with a negative PCR test after the first attack to clinical recurrence of symptoms compatible with COVID-19, which was confirmed by a positive PCR test.

A pilot study was conducted on 15 participants to assess clarity, applicability, and responsiveness to the questionnaire. The tools have been 
Table 3: Distribution of fatigue assessment scale points among participants:

\begin{tabular}{llccccc}
\hline & & $\begin{array}{c}\text { Never } \\
\mathbf{N}(\%)\end{array}$ & $\begin{array}{c}\text { Sometimes } \\
\mathbf{N}(\%)\end{array}$ & $\begin{array}{c}\text { Regularly } \\
\mathbf{N}(\%)\end{array}$ & $\begin{array}{c}\text { Often } \\
\mathbf{N}(\%)\end{array}$ & $\begin{array}{c}\text { Always } \\
\mathbf{N}(\%)\end{array}$ \\
\hline 1 & I am bothered by fatigue & $21(9.8)$ & $63(29.3)$ & $13(6.0)$ & $14(6.5)$ & $104(48.4)$ \\
\hline 2 & I get tired very quickly & $14(6.5)$ & $76(35.3)$ & $9(4.2)$ & $38(17.7)$ & $78(36.3)$ \\
\hline 3 & $\begin{array}{l}\text { I don't do much during } \\
\text { the day }\end{array}$ & $19(8.8)$ & $63(29.3)$ & $13(6.0)$ & $41(19.1)$ & $79(36.7)$ \\
\hline 4 & $\begin{array}{l}\text { I have enough energy for } \\
\text { everyday life. }\end{array}$ & $101(47.0)$ & $38(17.7)$ & $30(14.0)$ & $23(10.7)$ & $23(10.7)$ \\
\hline 5 & $\begin{array}{l}\text { Physically, I feel } \\
\text { exhausted. }\end{array}$ & $4(1.9)$ & $60(27.9)$ & $12(6.5)$ & $61(28.4)$ & $78(36.3)$ \\
\hline 6 & $\begin{array}{l}\text { I have problems to start } \\
\text { things }\end{array}$ & $27(12.6)$ & $69(32.1)$ & $5(2.3)$ & $48(22.3)$ & $66(30.7)$ \\
\hline 7 & $\begin{array}{l}\text { I have problems to think } \\
\text { clearly }\end{array}$ & $44(20.5)$ & $62(28.8)$ & $12(5.6)$ & $45(20.9)$ & $52(24.2)$ \\
\hline 8 & $\begin{array}{l}\text { I feel no desire to do } \\
\text { anything. }\end{array}$ & $20(9.3)$ & $68(31.6)$ & $12(5.6)$ & $63(29.3)$ & $52(24.2)$ \\
\hline 9 & $\begin{array}{l}\text { Mentally, I feel } \\
\text { exhausted }\end{array}$ & $18(8.4)$ & $73(34.0)$ & $17(7.9)$ & $51(23.7)$ & $56(26.0)$ \\
\hline 10 & $\begin{array}{l}\text { When I am doing } \\
\text { something, I can } \\
\text { concentrate quite well }\end{array}$ & $98(45.6)$ & $25(11.6)$ & $30(14.0)$ & $36(16.7)$ & $26(12.1)$ \\
\hline Median (range) of Fatigue assessment scale & & $\mathbf{3 6 . 0}(\mathbf{1 2 . 0 - 5 0 . 0})$ & \\
\hline
\end{tabular}

examined to validate their content by a panel of three experts from the National Cancer Institute, Cairo University. The reliability of tools was tested using Cronbach's Alpha test, and the reliability of the tool was 0.881 .

\section{Sample size estimation}

A previous study ${ }^{22}$ reported a $52.3 \%$ frequency of fatigue post-Covid-19. Based on these results, a minimum sample size of 196 patients is required with a margin of error of 0.05 and a 95\% confidence interval. To compensate for the moderate response rate and prevalence of chronic diseases, 300 individuals were initially invited to respond to the survey. The sample size was estimated using NQuery statistical package, version 7.0, Los Angeles, CA.

\section{Statistical Methods}

The Statistical Package of Social Sciences (SPSS) (version 26) was used to generate the results. The normality of the data was tested using the Kolmogorov-Smirnov single-sample test. Qualitative data are described as the number and percent. Numerical variables were presented as mean and standard deviation (SD) or median and (range). To compare the two groups, the Mann-whitney test was used, and the Kruskal-Wallis test was used to compare more than two groups. Spearman correlation was used to correlate continuous data. A p $\leq 0.05$ was considered significant.

\section{Ethical Consideration}

The approval of the Institutional Review Board of the National Cancer Institute was obtained. Data were collected anonymously, and after a full explanation of the aim of the study, participants were educated about the target and benefits of the analysis. Participation in the survey was voluntary. In addition, written consent (i.e., in the form of a question) was provided first. Respondents must agree and give their consent to proceed with the survey. The confidentiality of the data collected was ensured for the participants.

\section{Results}

The current study included 215 participants. The mean age of the 
Table 4: Association between sociodemographic characteristics and fatigue assessment score

\begin{tabular}{lcc}
\hline Characteristic & Fatigue Score & p-value \\
\hline Total & $36(12-50)$ & \\
\hline Age groups & & \\
\hline$<30$ & $36(14-49)$ & \\
$30-40$ & $37(12-50)$ & \\
$>40$ & $36(13-37)$ & 0.437 \\
\hline Sex & & \\
\hline Female & $37(15-50)$ & \\
Male & $35(18-40)$ & 0.363 \\
\hline Marital status & & \\
\hline Single & $33.5(14-48)$ & \\
Married & $37(12-50)$ & \\
Widow & $32.5(21-39)$ & \\
Divorced & $37(26-39)$ & 0.506 \\
\hline Occupation & & \\
\hline Employed & $35(12-50)$ & \\
Not Employed & $36(16-50)$ & \\
Students & $34.5(17-48)$ & 0.965 \\
\hline Need ICU & & \\
admission & & \\
\hline \multicolumn{1}{c}{ Yes } & $39(27-49)$ & \\
$\quad$ No & $33(11-50)$ & $<0.001$ \\
\hline
\end{tabular}

Values are presented as mean (range), ICU: intensive care unit. Statistical test used: Mannwhinny and Kruskal-Wallis test

Table 5: Correlation of fatigue scores with days after recovery from COVID-19, and duration of symptoms

\begin{tabular}{lcccc}
\hline & \multicolumn{2}{c}{$\begin{array}{c}\text { Duration of } \\
\text { symptoms }\end{array}$} & \multicolumn{2}{c}{ Duration after } \\
& recovery \\
& Rs & $\begin{array}{c}\mathbf{p} \\
\text { value }\end{array}$ & Rs & $\begin{array}{c}\mathbf{p} \\
\text { value }\end{array}$ \\
\hline Fatigue & 0.960 & $<0.001$ & -0.720 & $<0.001$ \\
Score & & &
\end{tabular}

Rs: Spearman correlation coefficient.

participants was $38.4 \pm 12.6$ years, $45.6 \%$ of the participants were between 30.040.0 years, 150 females $(69.8 \%)$, and 65 males $(30.2 \%)$. About three-quarters of the participants were married $(71.6 \%)$, two-thirds (63.7\%) were employed (Table $1)$.

The most presenting symptoms were bony ache $(74.0 \%)$, two-thirds of the participants complained of cough
$(60.5 \%), 43.7 \%$ suffered from headache, $57.2 \%$ experienced gastrointestinal symptoms, and $20.0 \%$ of the participants required admission to the intensive care unit (ICU). The median duration after recovery from COVID-19 was 40.0 days ranged from 15.0 to 180.0 days. The median duration of symptoms 18 days ranged from 7.0 to 40.0 days. 16.0 participants $(7.4 \%)$ were exposed to reinfection. The median duration of reinfection was about four months (Table 2).

The mean fatigue score was 36.0 and ranged between (12.0-50.0). Nearly half of the participants $(47.0 \%)$ complained about not having enough energy for everyday life, and $36.3 \%$ reported they always feel exhausted (table 3 ). There is no statistically significant association between sociodemographic data (age group, sex, marital status, and work) and the Fatigue Assessment Scale. Cases that needed ICU admission had a significantly greater average Fatigue Assessment Scale than those who did not require ICU admission (39.0 vs. 33.0; p-value < 0.001) (Table 4). A statistically significant negative association was found between the time after COVID-19 recovery and the fatigue assessment scale $(\mathrm{r}=-0.720$, $\mathrm{p}<0.001$ ); however, there was a positive statistically significant correlation between the duration of symptoms and the Fatigue Assessment Scale $(\mathrm{r}=0.960$, $\mathrm{p}<0.001$ ) (Table 5).

\section{Discussion}

The present study is a cross-sectional survey to assess the frequency of fatigue post-COVID-19 and whether the period after full recovery and the duration of symptoms affect fatigue severity. The average fatigue score was 36.0 and ranged between (12.0-50.0). A statistically significant negative association was found between the time after COVID-19 recovery and the fatigue assessment scale $(\mathrm{r}=-0.720, \mathrm{p}<0.001)$, nonetheless, there was a statistically significant positive

Vol. $40 \quad$ No. 1 January 2022


correlation between the duration of symptoms and the fatigue assessment scale $(\mathrm{r}=0.960, \mathrm{p}<0.001)$.

In this study, the mean age of the participants was $38.4 \pm 12.6$ years. Approximately $45.6 \%$ of the participants are between $30-40$ years. About twothirds of the sample $(63.7 \%)$ are employees (mostly health care workers). In a study by El Sayed et al., ${ }^{23}$ the mean age of the respondents was 36.58 (SD \pm 9.85) years. $103(51.5 \%)$ of the sample were employed and $97(48.5 \%)$ were unemployed. The high proportion of healthcare staff infected with COVID-19, not only in our cohort but globally, indicates that healthcare systems would be severely impacted.

Fatigue, dyspnea, cough, and fever are the most common clinical symptoms of COVID-19 patients as reported by Yang et al. ${ }^{24}$; however, in this study, bony pain and cough were the main presenting symptoms.

The current study found a high fatigue score, which is in agreement with Huang et al. $^{25}$, who noted that most patients experienced muscle ache, myalgia, and fatigue in the post-COVID-19 era. Many interventions used to combat the pandemic, such as social distancing, quarantining and isolation, have proven successful in slowing the spread of the virus that may have unintended consequences exacerbating fatigue in the COVID-19 recovery. These negative psychological consequences include anxiety, confusion, post-traumatic stress symptoms, depression, and anger. When taken into account, these consequences are thought to be a major contributor to fatigue. ${ }^{26}$

Concerning the early post-recovery period, high scores of fatigue were reported among the participants, and this finding is in agreement with Goyal et al. ${ }^{27}$, who noted that patients perceived sadness, loss of appetite, lethargy, inability to sleep, and ease of fatigability two weeks after recovery from COVID-19.
Moreover, Canadian researchers discovered that most survivors from SARS had a better physical improvement from their disease, but thirty-three percent registered a major decline in mental health. ${ }^{28}$ Another study reported that muscle weakness or fatigue and anxiety or depression were common, even at six months after symptom onset. ${ }^{29}$ Selfisolation, lockdown, and social isolation can have detrimental effects on the individual's physical and mental ability. Furthermore, feeling anxious and distressed about the pandemic while not participating in physical activity in the quarantine may lead to increased fatigue. ${ }^{30}$

In the current study, cases requiring ICU admission had a significantly higher fatigue score than those who did not $(39.0$ vs. 33.0; $p$-value $<0.001$ ). This finding is inconsistent with Townsend et al. ${ }^{22}$, who reported no association between COVID19 severity (need for hospitalization or critical care admission) and fatigue following COVID-19. For many patients, COVID-19-related fatigue can simultaneously occur in an environment where stress, anxiety, depression, and fear are rampant. ${ }^{26}$

In this study, a statistically significant negative correlation between the time after recovery from COVID-19 and fatigue assessment scale was reported $(\mathrm{r}=-$ $0.720, \mathrm{P}<0.001)$, and this aligns with the findings of El Sayed et al. ${ }^{23}$, who also revealed a statistically significant negative correlation between the fatigue assessment scale and the time after recovery from COVID-19. This inverse correlation could be attributed to the clearing up of the residual inflammation with the increase of the recovery period, and consequently, the psychological effect of isolation decreases.

In the current study, there was a statistically significant positive correlation between the duration of symptoms and the fatigue assessment scale $(\mathrm{r}=0.960, \mathrm{p}<0.001)$, and this study

Vol. 40 No. 1 January 2022


was unique regarding the correlation between the severity of the Fatigue Assessment Scale and the duration of symptoms.

\section{Conclusion}

Post-COVID-19 fatigue has been common after recovery from the novel coronavirus infection. The sociodemographic variables did not affect the fatigue score. Prolonged fatigue was associated with a longer duration of symptoms; however, it decreases over time after recovery. The use of Google docs for constructing, disseminating, and collecting data in a time of a pandemic is an appropriate and adequate tool that can be utilized worldwide. The creation of the questionnaire in Google format was simple, time-efficient, valid, and reliable.

Limitation: The response rate is lower in the online survey than the physical survey. The study requires a larger number of cases to obtain more solid data. Additionally, the assessment was done only once. It is a preliminary study that needs further research to detect the cause and mechanism of post-COVID-19 fatigue.

Abbreviations: (SARS-CoV-2): severe acute respiratory syndrome coronavirus2; (COVID-19): Coronavirus disease 2019; ICU: Intensive care unit.

\section{References}

1. Borghesi A, Zigliani A, Masciullo R, Golemi S, Maculotti P, Farina D, et al. Radiographic severity index in COVID-19 pneumonia: relationship to age and sex in 783 Italian patients. Radiol Med 2020; 1-4.

2. World Health Organization. WHO Director-General's opening remarks at the media briefing on COVID-19. Geneva; 2020. 3. Tian S, Hu N, Lou J, Chen K, Kang X, Xiang Z, et al. Characteristics of COVID-19 infection in Beijing. J Infect 2020; 80(4), 401-6.

4. Wang C, Pan R, Wan X, Tan Y, Xu L, Ho $\mathrm{CS}$, et al. Immediate psychological responses and associated factors during the initial stage of the 2019 corona virus disease (COVID-19) epidemic among the general population in China. International Journal of Int $\mathrm{J}$ Environ Res Public Health 2020; 17 (5):1729.

5. Drent M, Lower EE, De Vries J. Sarcoidosis-associated fatigue. Eur Respir J 2012; 40:255-263.

6. De Vries J, Drent M. Quality of life and health status in sarcoidosis: a review of the literature. Clin Chest Med 2008; 29:525-532. 7. Lam MH, Wing YK, Yu MW, Leung CM, Ma RC, Kong AP, et al. Mental morbidities and chronic fatigue in severe acute respiratory syndrome survivors: long-term follow-up. Arch Intern 2009;169(22):2142-7.

8. Xu XW, Wu XX, Jiang XG, Xu KJ, Ying $\mathrm{LJ}, \mathrm{Ma} \mathrm{CL}$, et al. Clinical findings in a group of patients infected with the 2019 novel coronavirus (SARS-Cov-2) outside of Wuhan, China: retrospective case series. BMJ. 2020; 368: m606.

9. Islam MF, Cotler J, Jason LA. Post-viral fatigue and COVID-19: lessons from past epidemics. Fatigue: Biomedicine, Health \& Behaviour 2020; (8:2):61-69.

10.Brooks SK, Webster RK, Smith LE, Woodland L, Wessely S, Greenberg N, et al. The psychological impact of quarantine and how to reduce it: rapid review of the evidence. Lancet 2020; (395):912-20.

11.National Institute for Health and Care Excellence. COVID-19 rapid guideline: managing the long-term effects of COVID19. 2020. https://www.nice.org.uk/ guidance/ng188.

12.Garg P, Arora U, Kumar A, Wig N. The "post-COVID" syndrome: how deep is the damage? J Med Virol. 2020; 93(2):673-674. 13. Outhoff K. Sick and tired of COVID-19: long haulers and post viral (fatigue) syndromes. South Afr Gen Pract J. 2020;1(4):132-133.

14.Butler M, Pollak TA, Rooney AG, Michael BD, Nicholson TR. Neuropsychiatric complications of COVID-19. British Medical Journal Publishing Group; 2020;7(10):875882.

15.Rayhan RU, Zheng Y, Uddin E, Timbol C, Adewuyi O, Baraniuk JN. Administer and collect medical questionnaires with Google documents: a simple, safe, and free system. Appl Med Inform 2013; (33): 12-21.

16. Michielsen H, De Vries J, Van Heck GL. Psychometric qualities of a brief self-rated 
fatigue measure the fatigue assessment scale. J sychosom Res 2003; 54(4):345-52.

17.Den Oudsten BL, Van Heck GL, Van der Steeg AF, Roukema JA, De Vries J. Second operation is not related to psychological outcome in breast cancer patients. Int $\mathbf{J}$ Cancer 2010; 126:1487-1493.

18.Dittner AJ, Wessely SC, Brown RG The assessment of fatigue. A practical guide for clinicians and researchers. J Psychosom Res. (2004); 56:157-170

19.De Vries J, Michielsen HJ, Van Heck GL. Assessment of fatigue among working people: a comparison of six questionnaires. Occup Environ Med 2003; 60:i10-i15.

20.Cano-Climent A, Oliver-Roig A, CabreroGarcia J, de Vries J, Richart-Martínez M. The Spanish version of the Fatigue Assessment Scale: reliability and validity assessment in postpartum women. Peer J 2017; 5: e3832

21.Cumming TB, Mead G. Classifying poststroke fatigue: optimal cut-off on the Fatigue Assessment Scale. J Psychosom Res 2017; 103:147-149.

22. Townsend L, Dyer AH, Jones K, Dunne J, Mooney A, Gaffney F, et al. Persistent fatigue following SARS-CoV-2 infection is common and independent of severity of initial infection. PLoS One 2020; 15(11): e0240784. 23.

24.El Sayed S, Shokry D, Gomaa S. PostCOVID-19 fatigue and anhedonia: A crosssectional study and their correlation to postrecovery period. Neuropsychopharmacol Rep 2020; (00):1-6.
25. Yang R, Li X, Liu H, Zhang X, Xiong Q, Luo Y, et al. Chest CT severity score: an imaging tool for assessing severe COVID-19. Radiology Cardiothoracic Imaging 2020; (2):2.

26.Huang C, Wang Y, Li X, Ren L, Zhao J, $\mathrm{Hu} \mathrm{Y}$, et al. Clinical features of patients infected with 2019 novel coronavirus in Wuhan, China. Lancet 2020; 395(10223):497-506.

27.Morgul E, Bener A, Atak M, Akyel S, Aktaş S, Bhugra D, Ventriglio A, Jordan TR. COVID-19 pandemic and psychological fatigue in Turkey. Int J Soc Psychiatry 2020; $1-8$.

28. Goyal K, Chauhan P, Chhikara K, Gupta P, Singh MP. Fear of COVID: First suicidal case in India. Asia J Psychia 2019; (49): 101989.

29.Tansey CM, Louie M, Loeb M, Gold WL, Muller MP, de Jager J, et al. One-year outcomes and health care utilization in survivors of severe acute respiratory syndrome. Arch Intern Med 2007; (167): 1312-20.

30.Huang C, Huang L, Wang Y, Li X, Ren L, Gu X, Kang L, et al. 6-month consequences of COVID-19 in patients discharged from hospital: a cohort study. Lancet; 2021(397) :220-232.

31.Taylor S. The Psychology of Pandemics: Preparing for the Next Global Outbreak of Infectious Disease; Cambridge Scholars Publishing: Cambridge, UK, 2019. 